\title{
'Becoming da Vinci' Exercise Ignites the Inventor Spirit
}

\author{
Kathleen Allen (University of Southern California)
}

KEYWORDS: Entrepreneurship, Innovation, Teaching Methods.

Students often have a hard time understanding the difference between an invention and an innovation and, likewise, the difference between incremental and disruptive innovation. I developed this exercise to help students delve into the mind of an inventor. The inventor mindset is an experience that most students never have; yet, many great entrepreneurial ventures of our time started out with ideas that became inventions in a laboratory with no thought for a possible market. Much of what is created today are innovations and "me-too" applications, so challenging students to create something novel is an important but difficult undertaking for them. Furthermore, as entrepreneurs, your students may one day work with an inventor to commercialize a new product, so it's important that they have some understanding of how inventors think and work.

For purposes of this exercise, we define invention as an original idea to solve a problem. That solution can be in the form of a machine, a physical process or a product. We avoid inventions that involve "composition of matter" like drugs and such in an effort to keep things simple and understandable for the entire class. An innovation, by contrast, extracts commercial value from an idea. It is often the application that arises from an invention or it may be an improvement on an existing product. It is also the process by which an invention is commercialized.

\section{Process matters more than problems}

This exercise is fairly simple in terms of preparation and instructions. Students are given two weeks to identify a problem that calls for a "new to the world" solution. Students are asked to avoid complex problems that may require multiple inventions (solving global climate change or major city traffic come to mind) and instead stick to simpler problems. It's not the problem itself that is most important in this exercise; it's the process students will undertake to complete the assignment. As part of the assignment, students are asked to reflect on

the process they go through to identify a problem and create a novel solution. Since the exercise calls for an invention, students are challenged to come up with a product, not a new business model, service, or other solution that would not be categorized strictly as an invention. Students are not expected to prove that their product is a commercially viable solution.

During the students' presentations of their "inventions," it becomes clear how well they understand the concepts of invention and innovation. Most students will create something that already exists; and their classmates will be quick to point that out, which presents an opportunity to discuss the differences between an invention and an innovation. The students find this discussion very valuable, but it is made more memorable by bringing a real inventor to class to view and comment on their "inventions." Once the student presentations are completed, you can then call on the inventor guest to talk about the process he or she goes through to invent things that are novel, patentable and have impact.

\section{Exercise Objectives}

- To apply critical thinking to a problem and to the process chosen to find a solution

- To challenge students to look beyond the obvious and seek a novel solution

- To understand the difference between invention and innovation

\section{Exercise Format}

1. Instructor Preparation: Identify an inventor at your university who has had several inventions, at least some of which have been commercialized. For example, I chose, arguably, the most prolific inventor at the University of Southern California, who has change-the-world inventions in robotics, orthodontics, the oil industry and manufacturing. $\mathrm{He}$ is also able to

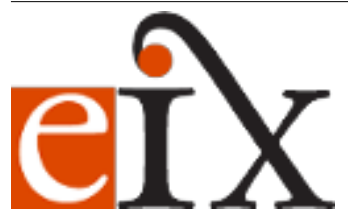

Copyright ( $) 2017$ The Authors. Entrepreneur \& Innovation Exchange is published at EIX.org. This is an open access article under the terms of the Creative Commons Attribution-NoDerivs License, which permits use and distribution in any medium, provided the original work is properly cited and no modifications or adaptations are made. View EIX.org Authorship Terms at https://eix.org/terms 
talk to students about his unique life as an inventor and provide insights into how he creates. You will probably discover that talking with inventors is often very different from talking with the average speaker you might bring to class. Don't be concerned that they aren't necessarily charismatic speakers. In my case, my inventor's delivery style is very different from the stylized, entertaining presentations we generally see in business schools-his delivery is low key, Zen-like - so you may think that students would get bored quickly or fall asleep listening to his soothing voice. Quite the opposite is true. They are enthralled by this person who looks at the world very differently from the way they do and they are fascinated with how he finds solutions to problems. Once you have found an inventor, you will need to decide when to do the exercise.

2. The best timing for this exercise is when you have planned to talk about the concept of innovation because it enables students to apply what they have learned from the class discussion to the exercise and find out if they have really understood the concepts.

3. Students receive the instruction sheet on the day the assignment is introduced and can ask clarification questions.

4. Students have two weeks to complete the assignment.

5. On the due date students come to class prepared to describe in two to three minutes how they came up with the problem and then show a visual of their solution.

6. For each presenter, the guest inventor can comment or ask questions of the student and an open discussion can ensue. I suggest that no more than five students present for the inventor. If you have the students submit their assignments before class, you can scan them to find the most interesting to call on to present to the inventor.

7. After the final presenter, the guest inventor may summarize some key thoughts about what the students did and then talk about his/her own experiences as an inventor.

\section{Introducing the Exercise}

Ideally, the topic for the class in which you will be assigning the da Vinci exercise should be innovation. I like to add a bit of history to the topic by introducing the concept of the Medici Effect. The Medici Effect, coined by Frans Johannsen in his book by the same name, refers to the explosion of ideas in art, science, literature and politics brought about through the efforts of a 15th Century banking family: the Medicis of Florence, Italy. The Medicis brought together people from every walk of life and every creative discipline and funded them to create in a way that had never been seen previously. The Medici Effect disrupted traditional lines of association and encouraged new disruptive creations at the intersection of multiple disciplines: art and science, science and politics, and so forth. Depending on your plans for this session, you can go deeper into the Medicis' very fascinating story. The Medici Effect example provides a good introduction to the concepts of invention and disruption, because both typically come about when ideas that normally don't go together are juxtaposed. Directional innovation (also called incremental) is a way to improve on a product in fairly predictable ways and is the most common form of innovation. By contrast, intersectional ideas -- which bring together unrelated concepts in new and surprising ways -- take us in brand new directions; they disrupt current thinking and create new platforms for incremental innovation. For example, the solar panel was inspired by the biology of leaves and da Vinci's canal system in Florence was inspired by tree branches. You might want to read The Medici Effect: What Elephants and Epidemics can Teach Us about Innovation by Frans Johansson and Teresa M. Amabile to stimulate more examples and encourage students to do their inventions at the intersection.

Your introduction could also take on the concept of associative barriers that often prevent entrepreneurs from coming up with the best solutions. When we hear or see something, our minds immediately associate it with something we know because the mind typically follows the simplest path. If we say, for example, that Jon Chang is a professor, depending on your particular perspective about professors, a chain of associations may appear: Jon is a man, he's Asian, he's politically left of center, he's a book worm, etc. The reality is that none of these attributes may describe Jon who actually is a Caucasian woman married to an Asian man. She's independent politically and only reads when it's necessary for her research. If you have low associative barriers, you tend to be more comfortable connecting dissimilar ideas and concepts. Consequently, your chances of coming up with novel solutions is greater 
than if you had high associative barriers that would cause you to limit the scope of possible solutions.

\section{Tips for Instructors}

- Encourage students to look for real problems and not fall prey to copying something that already exists. When a student does imitate an existing solution, they find out rather quickly because someone in the class will call them on it.

- Depending on the course in which you're using this exercise, you can choose to focus the scope of problems on social entrepreneurship problems, problems that involve technology solutions, problems related to students or some other group, or problems faced by small businesses.

- If you have a large class, perhaps take volunteers to present in front of the inventor or, as suggested earlier, you can scan the assignments ahead of class to choose the most interesting. The rest of the students can present after the inventor leaves. Asking an inventor to listen to 35 inventions is probably not reasonable. If you don't want 35 presentations, you can simply take volunteers or ask students to put a video of their 2 minute presentation on a platform like YouSeeU or in Blackboard.

- After a student presentation, ask the class to critique or comment on whether the solution presented qualifies as an invention or perhaps an innovation. This can be done in a constructive way, often with humor.

- Grading the assignment: As with all assignments, a portion of the grade should be for following the instructions. Beyond that, the following should be considered:

- Did the student demonstrate sufficient critical thinking in identifying a problem? Was it a compelling problem that could, if commercialized, impact a significant number of people?

- Did the solution demonstrate that the student inventor was aware of existing solutions?

-Was the solution novel and not obvious?

\section{Questions for Discussion Post Presentations}

1. What are the key distinctions between an invention and an innovation?

1. An invention is an original creation that may or may not qualify for intellectual property protection via a patent. In general terms, it is a useful device or process that has not existed previously. An invention may or may not be commercialized; that is, the vast majority of inventions never become products or processes in the marketplace.

2. An innovation is the result of extracting marketable, economic value from an idea. The innovation can be incremental, built on an existing innovation generally to improve on it or differentiate it. It can also be disruptive, changing the game by making previous technology or ways of doing things obsolete.

2. Are we seeing more inventions or incremental innovations today?

1. In general, we are seeing more incremental innovations or improvements on existing technologies because it's easier and quicker than inventing something from scratch.

\section{What will you take away from this} experience with invention?

1. This is an open-ended question designed to have students reflect on what the assignment meant to them.

\section{Appendix: \\ da Vinci Exercise: Introduction for Students}

This exercise is very different from most that you will undertake this semester because it asks you to use your critical thinking and creative skills in a very unusual way. You are going to put yourself into the mind of an inventor and create something that has not existed previously. Keep in mind that much of what you're seeing today is incremental innovation, which builds on something that already exists. The iPad was a singular improvement on the Apple Newton. It was not an invention. It was an innovation, which is a novel idea that has commercial value.

Keep in mind when you're thinking about invention that 
exceptional inventions have two critical aspects:

1. They are unique - new to the world.

2. They have an impact (the bigger the better).

Clearly, these two metrics are relative and difficult to measure, but your goal should be to come up with something that goes beyond the obvious and could potentially benefit a lot of people. Why? Because inventions take a lot of time and money to build and take to market, so spending your creation time on something that will help a lot of people makes sense. At the same time, stay away from huge, complex problems like traffic that likely require multiple inventions and the cooperation of several entities.

\section{Assignment Instructions}

1. Choose a meaningful problem that an entrepreneur could solve, that affects a significant number of people and that requires an inventive solution. The solution should not be obvious.

2. In one page, do the following:

1. Briefly describe the problem and the solution.

2. Briefly describe the process you went through to come up with both. This is a reflection piece, not simply listing the things you did. Why did you do them?

3. On the second page, you may sketch out a picture of your solution or you may do a primitive prototype and put a picture of that on the second page. If you do have a physical prototype, please plan to bring it when you make your presentation. We are not expecting perfection, just a demonstration of your creative thinking process.

4. Submit ONE FILE containing both pages to Blackboard (or to another assignment platform you are using).

5. Come to class prepared to do a two-minute presentation and answer questions.

Additional Search Terms: entrepreneurship courses, teaching ideas, teaching resources, classroom ideas, entrepreneurship classes, business schools, business school classes, entrepreneurship students, professors 